\title{
GLOBAL AEROSOL DIRECT RADIATIVE EFFECT FROM CALIOP AND C3M
}

\author{
Dave Winker ${ }^{*}$, Seiji Kato ${ }^{1}$, and Jason Tackett ${ }^{2}$ \\ ${ }^{1}$ NASA Langley Research Center, Hampton, VA, 23681 *email: david.m.winker@nasa.gov \\ ${ }^{2}$ SSAI, Hampton, VA, 23666
}

\begin{abstract}
Aerosols are responsible for the largest uncertainties in current estimates of climate forcing. These uncertainties are due in part to the limited abilities of passive sensors to retrieve aerosols in cloudy skies. We use a dataset which merges CALIOP observations together with other A-train observations to estimate aerosol radiative effects in cloudy skies as well as in cloud-free skies. The results can be used to quantify the reduction of aerosol radiative effects in cloudy skies relative to clear skies and to reduce current uncertainties in aerosol radiative effects.
\end{abstract}

\section{INTRODUCTION}

Aerosols affect the Earth's radiation budget by scattering sunlight back to space and by absorbing sunlight before it reaches the surface. Model estimates of global aerosol radiative effects in cloudy-skies depend in part on cloud albedo and on the relative vertical distribution of aerosol and cloud. This represents a major source of uncertainty in model estimates of aerosol forcing, as the aerosol vertical distribution in models is poorly constrained and there is a large diversity between models ${ }^{1}$. Additionally, global models do a poor job at predicting the cloud cover and top height of shallow warm clouds ${ }^{2}$. On the other hand, published estimates of global aerosol radiative effects based on satellite observations (e.g. [3]) have been hampered by a reliance on passive satellite sensors, which are largely restricted to aerosol retrievals in clear-sky conditions. Assumptions or model estimates are then required to extend the clear-sky estimates to all-sky conditions. This limitation is particularly important for aerosol located above bright, low clouds. These estimates based on satellite observations consistently predict larger aerosol cooling than model based estimates. There are many factors contributing to this discrepancy, but a large part remains unexplained.
These uncertainties can be reduced using observations from the CALIOP lidar, on the CALIPSO satellite, which retrieves the vertical distribution of aerosol extinction in both clear and cloudy skies ${ }^{4}$. Chand et al. [5] and have used observations from CALIOP and MODIS in a regional study of the radiative effects of aerosol above cloud. Oikawa et al. [6], using a different approach, produced the first global all-sky estimate. Here, using a different approach from [5] and [6], we combine observations from CALIPSO and the A-train to estimate global aerosol radiative effects in both clear and cloudy skies.

\section{DIRECT RADIATIVE EFFECT}

Direct aerosol radiative forcing (DARF), as it is usually defined, refers to the radiative effect of anthropogenic aerosol in the present data relative to pre-industrial conditions. This inherently requires the use of models to estimate aerosol radiative effects in pre-industrial conditions. Here, we estimate the aerosol direct radiative effect (DRE), defined as the perturbation in diurnally averaged radiative fluxes due to both natural and anthropogenic aerosol. This quantity is more directly observable and is also more relevant to the radiative impact of aerosol on the present-day Earth radiation budget.

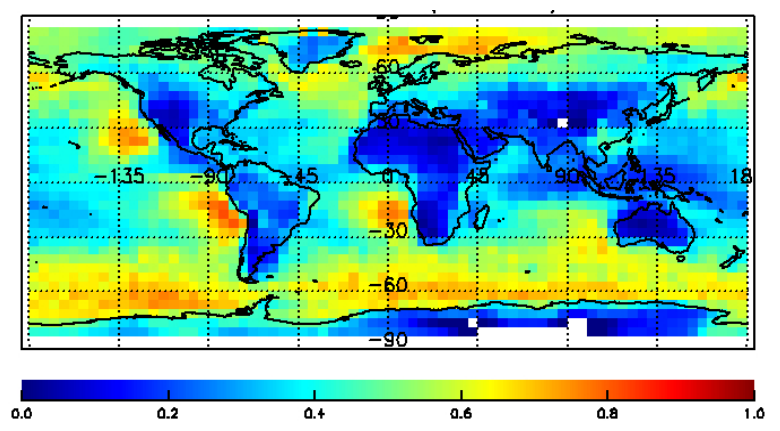

Figure 1. Mean low cloud amount from CALIOP, 2008 annual average. 
Significant amounts of aerosol are located above low clouds in certain regions. Figure 1 shows the global distribution of low clouds, having tops typically less than $2 \mathrm{~km}$. Figure 2 shows aerosol scale heights from the CALIPSO Level 3 aerosol product $^{7}$ and Figure 3 shows AOD of aerosol below thin clouds and above low clouds.

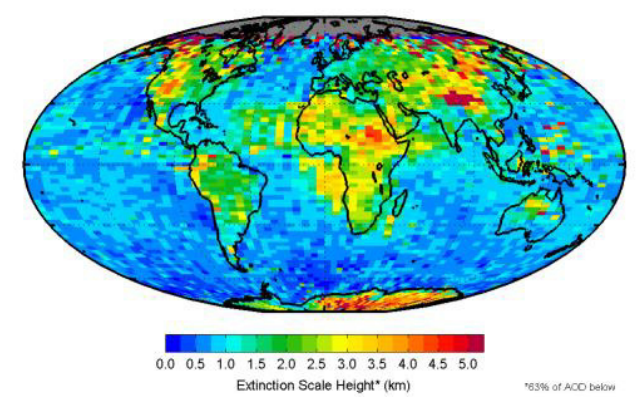

Figure 2. Aerosol scale height, defined as the height at which $63 \%$ of the AOD lies below, for August 2008.

Figure 3 shows regions where significant aerosol is located in cloudy columns. Three primary regions are seen in August 2008 where significant AOD is located above low opaque clouds: the Atlantic dust transport region, west of the coast of southern Africa, and the Arabian sea.

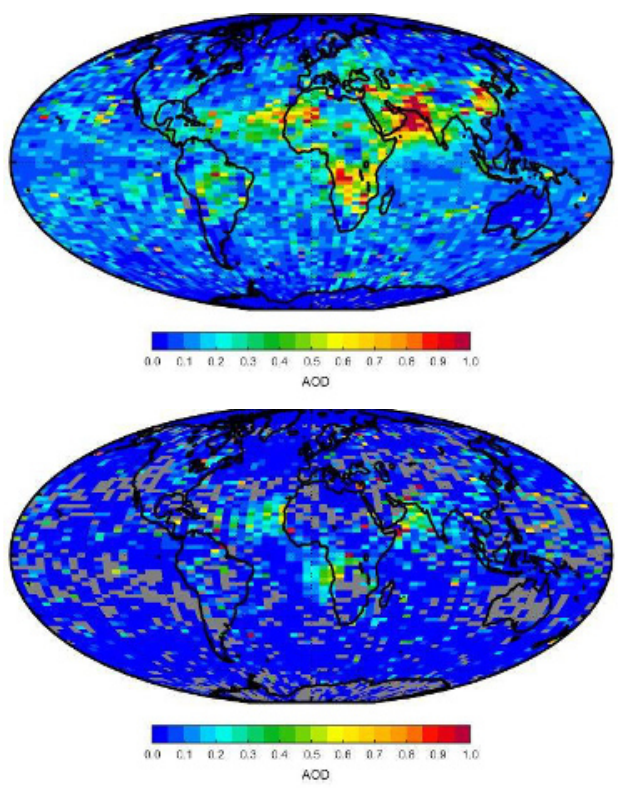

Figure 3. Upper panel: AOD in columns containing optically thin cloud. Lower panel, AOD above low opaque cloud
In addition to aerosol extinction at $532 \mathrm{~nm}$, calculation of aerosol DRE requires aerosol spectral properties, cloud properties, surface albedo, and radiative transfer calculations. Our estimates are based on the CERES-MODISCALIPSO-CloudSat $(\mathrm{C} 3 \mathrm{M})$ product ${ }^{7}$. The C3M product contains profiles of SW and LW irradiance computed from instantaneous, collocated MODIS aerosol/cloud data and profiles from CALIPSO and CloudSat, all matched to CERES footprints. Aerosol extinction profiles in both clear and cloudy skies come from CALIOP. Aerosol absorption is estimated using information on aerosol type and optical properties from a combination of CALIOP and the MATCH global aerosol model. Aerosol absorption for the various aerosol species is based on the OPAC optical properties database ${ }^{8}$. Diurnally averaged fluxes are derived and used to estimate annual and seasonal mean DRE.

\section{RESULTS}

Diurnally averaged fluxes have been derived from $\mathrm{C} 3 \mathrm{M}$ and used to estimate annual and seasonal mean DRE. Table 1 gives annual mean shortwave (SW) aerosol DRE at the top of the atmosphere (TOA). Cloudy-sky DRE is derived from all-sky and clear-sky DRE using:

$$
\mathrm{DRE}_{\mathrm{cldy}}=\mathrm{DRE}_{\mathrm{all}}-\left(1-\mathrm{A}_{\mathrm{c}}\right) \mathrm{DRE}_{\text {clear }} / \mathrm{A}_{\mathrm{c}}
$$

where $A_{c}$ is the cloud fraction.

Table 1. 2008 global annual mean SW TOA aerosol DRE.

\begin{tabular}{|l|c|}
\hline & Aerosol DRE, W/m² \\
\hline All-sky & -2.34 \\
\hline Clear-sky & -3.30 \\
\hline Cloudy-sky & -1.93 \\
\hline
\end{tabular}

It can be seen that cloudy-sky aerosol DRE is less negative than in clear-skies. This is due to two effects: masking of aerosol radiative effects by 
overlying cloud, and warming effects of absorbing aerosol over clouds and other bright surfaces.
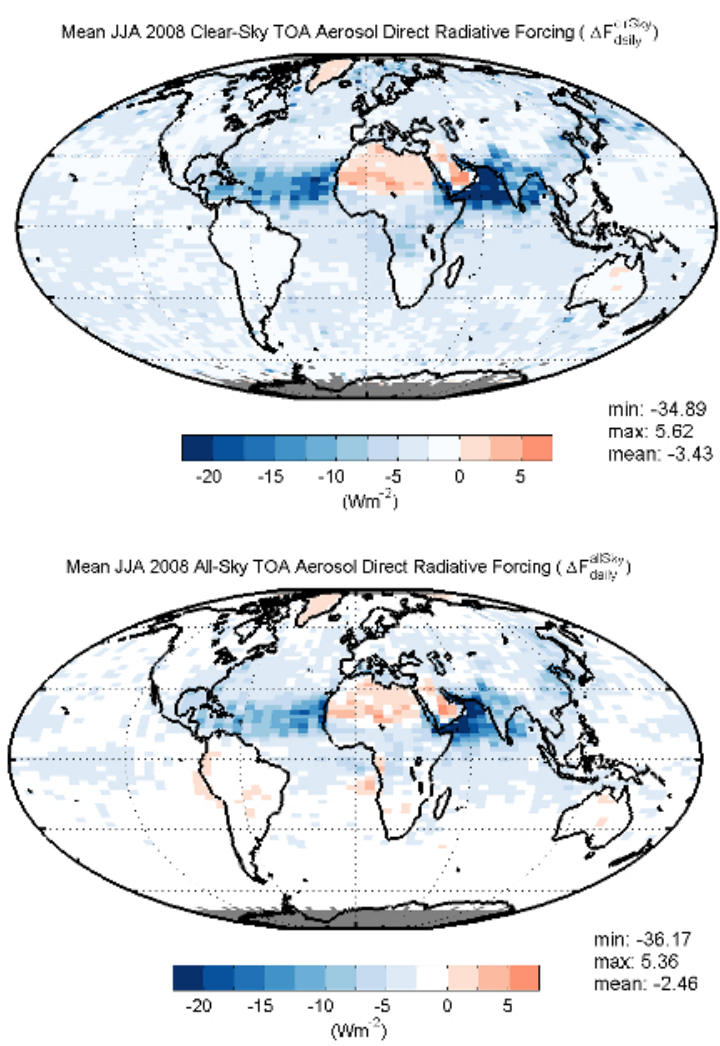

Figure 4. Shortwave TOA aerosol DRE, JJA 2008. Top: Clear-sky only. Bottom: All-sky.

Figure 4 compares the global distribution of aerosol DRE in clear and cloudy skies. Blue shades indicate net aerosol cooling at TOA. Reddish shades indicate net aerosol warming. For absorbing aerosol, there is a critical value of aerosol single scatter albedo where the aerosol effect goes from cooling to warming. The magnitude of the critical value depends on the magnitude of the underlying column (Figure 5).

In the top panel of Figure 4, showing clear-sky effects only, a net warming effect is only seen over the relatively bright surfaces of the Sahara and middle Eastern deserts and the snow-covered surface of Greenland. The differences seen between the upper and lower panels are due to absorbing aerosol above bright clouds. Figure 4 shows results for JJA, which is the burning season in Brasil and southern Africa. The net aerosol warming in these regions offsets part of the clearsky cooling resulting in a less negative global mean aerosol DRE.

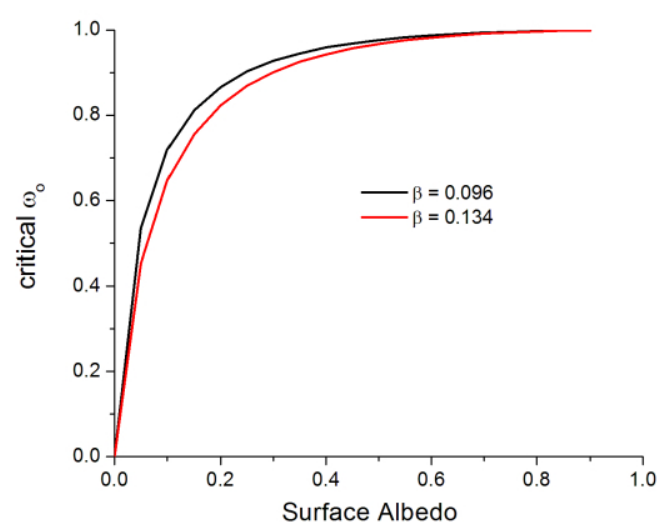

Figure 5. Critical value of aerosol single scatter albedo as a function of surface albedo. The two curves correspond to fine mode and coarse mode aerosol particles having upscatter fraction, $\beta$.

\section{SUMMARY}

An approach combing passive and active observations with model data has been used to estimate aerosol direct radiative effects in both clear and cloudy skies. The results show that allsky DRE is less negative than in clear skies, due both to the masking effect of clouds and the warming effect of absorbing aerosol. This result helps to explain the discrepancy between model and observational estimates of aerosol radiative effects. Next steps include an analysis of the variability of DRE at regional scales, and an analysis to estimate uncertainties of the derived DRE values.

\section{REFERENCES}

[1] Koffi, B., M. Schulz, F.-M. Bréon, J. Griesfeller, D. M. Winker, Y. Balkanski, S. Bauer, T. Berntsen, M. Chin, W. D. Collins, F. Dentener, T. Diehl, R. C. Easter, S. J. Ghan, P. A. Ginoux, S. Gong, L. W. Horowitz, T. Iversen, A. Kirkevag, D. M. Koch, M. Krol, G. Myhre, P. Stier, and T. Takemura, 2012: "Application of the CALIOP Layer Product to evaluate the vertical 
distribution of aerosols estimated by global models: Part 1. AeroCom phase I results", $J$. Geophys. Res., 117, D10201, doi:10.1029/2011JD016858.

[2] Nam, C. C. W., S. Bony, J.-L. Dufresne, and H. Chepfer, 2012: "The 'too few, too bright' tropical low-cloud problem in CMIP5 models, Geophys. Res. Lett. 39,

doi:10.1029/2012GL053421.

[3] Bellouin, N., A. Jones, J. Haywood, and S. A. Christopher, 2008: Updated estimate of aerosol direct radiative forcing from satellite observations and comparison against the Hadley centre climate model. J. Geophys. Res., 113 (D10205).

[4] Winker, D. M., M. A. Vaughan, A. H. Omar, Y. Hu, K. A. Powell, Z. Liu, W. H. Hunt, and S. A. Young, 2009: "Overview of the CALIPSO Mission and CALIOP Data Processing Algorithms", J. Atmos. Oceanic Technol., 26, 2310-2323, doi:10.1175/2009JTECHA1281.1.

[5] Chand, D., R. Wood, T. L. Anderson, S. K. Satheesh, and R. J. Charlson, 2009: "Satellitederived direct radiative effect of aerosols dependent on cloud cover", Nat. Geosci. 2, 181184, doi:10.1038/ngeo437.

[6] Oikawa, E., T. Nakajima, T. Inoue and D. Winker, 2013: "A study of the shortwave direct aerosol forcing using ESSP/CALIPSO observation and GCM simulation", J. Geophys. Res., 118, 3687-3708, doi:10.1002/jgrd.50227.

[7] Winker, D. M., J. L. Tackett, B. Getzewich, Z. Liu, M. A. Vaughan, and R. R. Rogers, 2013: "The global 3-D distribution of tropospheric aerosols as characterized by CALIOP", Atmos. Chem. Phys., 13, 3345-3361, doi:10.5194/acp-133345-2013

[7] Kato, S., S. Sun-Mack, W. F. Miller, F. G. Rose, Y. Chen, P. Minnis, and B. A. Wielicki, 2010: "Relation of cloud occurrence frequency, overlap, and effective thickness derived from CALIPSO and CloudSat merged cloud vertical profiles", J. Geophys. Res., 115, D00H28, doi:10.1029/2009JD012277.

[8] Hess, M., P. Koepke, and I. Schult, 1998: Optical Properties of Aerosols and Clouds: The Software Package OPAC. Bull. Amer. Meteor. Soc. 79, 831-844. 